\section{ALS Awareness Month — May 2017}

May is ALS Awareness Month, observed to raise awareness of and foster research for amyotrophic lateral sclerosis (ALS), also known as Lou Gehrig's disease. ALS is a progressive, fatal, neurodegenerative disorder of upper and lower motor neurons. The cause of ALS is not known, and no cure exists.

In October 2010, the Agency for Toxic Substances and Disease Registry (ATSDR) launched the congressionally mandated National ALS Registry (https://wwwn.cdc.gov/als/) to collect and analyze data regarding persons in the United States with ALS. The goals of the registry are to determine the incidence and prevalence of ALS, characterize the demographics of persons living with ALS, and examine possible risk factors for the disease.

In August 2016, ATSDR released its second prevalence report, which indicated an estimated 16,000 persons $(5.0$ per 100,000 population) were living with ALS in 2013. ALS remains more common among whites, males, non-Hispanics, and persons aged 60-69 years. The registry uses data from existing national databases, as well as the registry's online system to track ALS cases. Online registrants can also take surveys regarding potential risk factors for the disease.

A new National ALS Biorepository allows researchers to request high-quality biologic specimens to study ALS. Both in-home and postmortem specimens are being collected from interested patients enrolled in the National ALS Registry. Epidemiologic data from patient surveys will be matched with patient specimens, making the biorepository a rich data source for ALS research.

ATSDR is collaborating with the ALS Association (https:// www.alsa.org), the Muscular Dystrophy Association (https:// www.mda.org), the Les Turner ALS foundation (http://www. lesturnerals.org), and other organizations to spread awareness about the National ALS Registry. Additional information is available at https://www.cdc.gov/als.

\section{Community Preventive Services Task Force Recommends Interventions to Increase Healthier Foods and Beverages in Schools}

The Community Preventive Services Task Force recently posted new information about four findings on its website: 1) Obesity: Meal and Fruit and Vegetable Snack Interventions to Increase Healthier Foods and Beverages Provided by Schools*; 2) Obesity: Supporting Healthier Snack Foods and Beverages Sold or Offered as Rewards in Schools ${ }^{\dagger}$; 3) Obesity: Multicomponent Interventions to Increase Availability of Healthier Foods and Beverages in Schools ${ }^{\S}$; and 4) Obesity: Increasing Water Access in Schools.

Established in 1996 by the U.S. Department of Health and Human Services, the task force is an independent, nonfederal panel of public health and prevention experts whose members are appointed by the director of CDC. The task force provides information for a wide range of persons who make decisions about programs, services, and other interventions to improve population health. Although CDC provides administrative, scientific, and technical support for the task force, the recommendations developed are those of the task force and do not undergo review or approval by CDC.

\footnotetext{
*https://www.thecommunityguide.org/findings/obesity-meal-fruit-vegetablesnack-interventions-increase-healthier-foods-beverages-schools.

$\dagger^{\dagger}$ https://www.thecommunityguide.org/findings/obesity-supporting-healthiersnack-foods-and-beverages-sold-or-offered-rewards-schools.

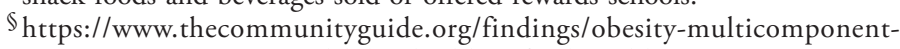
interventions-increase-availability-healthier-foods-and-beverages.

Shtps://www.thecommunityguide.org/findings/obesity-increasing -water-access-schools.
} 